\title{
Building Scientist Capacity in Knowledge Translation: Development of the Knowledge Translation Planning Template
}

\author{
Melanie Barwick
}

\author{
"A little knowledge that acts is worth infinitely" \\ more than much knowledge that is idle.
}

Kahlil Gibran (1883-1931)

Poet, philosopher, and artist

\begin{abstract}
The last fifteen years have seen a fundamental shift in the importance of knowledge translation in health research and clinical care. Health research funders have incorporated knowledge translation into their missions, strategic directions, and funding opportunities, encouraging knowledge translation and implementation science and requiring knowledge translation practice from researchers working across the health research pillars - basic, clinical, health services, and population health. Healthcare and research organizations have changed their landscape as well, hiring knowledge translation practitioners to bridge research and practice for a range of knowledge users. Universities are shifting criteria for academic promotion to incorporate knowledge translation. Growing attention to knowledge translation in research, practice, and scholarship has created a need for researchers and practitioners to develop knowledge translation skills and competencies related to their research, scholarship, and organizational activities. The Knowledge Translation Planning Template was developed to support knowledge translation planning for scientists in health and other sectors. This article provides an overview of the rationale for its development, introduces the tool components, and describes preliminary indicators of impact.
\end{abstract}

\section{Introduction}

Effective knowledge translation is viewed as essential for closing the research-to-practice gap in health research and clinical care (Balas \& Boren, 2002; Morris et al., 2011) and ensuring a more efficient and effective use of research innovations in practice and policy. Knowledge translation is a global consideration (Tetroe et al., 2008). Health research funders in Canada, as elsewhere, have incorporated knowledge translation into their mission, strategic directions, and funding opportunities, thereby encouraging knowledge translation and implementation science and requiring knowledge translation practice from researchers working across the health research pillars - basic, clinical, health services, and population health (Ellis, 2014; Tetroe et al., 2008). Healthcare and research organizations have changed their landscapes as well, hiring knowledge translation practitioners to fulfill this responsibility (Barwick, Bovaird, \& McMillen, manuscript in preparation).
The growing attention to knowledge translation in research and practice has created a need for both researchers and practitioners to develop new skills and competencies in knowledge translation practice, related to their research, academic, or to organizational activities. It is in this context that the Knowledge Translation Planning Template was developed to support knowledge translation planning. There is increasing expectation globally that researchers will be able to demonstrate the "real world" impact of their research, requiring them to think strategically about their work and how it can be applied in practice (e.g., Collie et al., 2016). The first step in achieving this aim is to consciously plan their knowledge translation activities. Few studies have explored the knowledge translation activities of researchers (e.g., Barwick et al., in preparation; Nedjat et al., 2014; Newton et al., 2007; Wilson et al., 2010), and we know of no other tools focused on supporting this important activity other than several that have been based on the Knowledge Translation 


\section{Development of the Knowledge Translation Planning Template}

\section{Melanie Barwick}

Planning Template. This article provides an overview of the rationale for the tool's development, introduces the tool components, and describes preliminary indicators of impact.

\section{Shifting the Research Paradigm: Changes at the Funding Agency Level}

The Canadian Institutes of Health Research (CIHR; cihr-irsc.gc.ca) has an explicit mandate to excel in "the creation of new knowledge and its translation into improved health for Canadians, more effective health services and products, and a strengthened Canadian health system" (Ellis, 2014). CIHR has targeted promotion of knowledge translation research through funding grants, including strategic initiatives; built knowledge translation networks that recognized collaboration by researchers and knowledge users; strengthened and expanded their internal knowledge translation capacity, which included advising CIHR on internal peer review for effective knowledge translation assessment in research application; and supported and recognized knowledge translation excellence through an annual award for excellence in knowledge translation. CIHR also instituted funding for Canada Research Chairs in Knowledge Translation, following in the direction of the Canadian Health Services Research Foundation (CHSRF) which had emerged several years earlier in 1997, although it is now the Canadian Foundation for Healthcare Improvement (CFHI; cfhi-fcass.ca). Further efforts to link knowledge translation activities to impact are evident in the knowledge translation section of the Canadian Common CV (CVV; ccv-cvc.ca), utilized by the three Federal funding bodies - the CIHR, the Natural Sciences and Engineering Research Council (NSERC; nserc-crsng.gc.ca), and the Social Sciences and Humanities Research Council (SSHRCC; sshrc-crsh.gc.ca), and in CIHR's final report criteria (CIHR, 2012), which request detailed information about the knowledge translation activities related to the completed CIHR funded project, including knowledge users, form of engagement, knowledge translation activities and deliverables, and impact (evaluation).

In Canada, CIHR and CHSRF have been instrumental in building knowledge translation science through new funding opportunities. Specific funding opportunities were directed at encouraging integrated knowledge translation, defined as "an approach to doing research that applies the principles of knowledge translation to the entire research process" and involving knowledge users as equal partners alongside researchers to lead to research that is more relevant to, and more likely to be useful to, the knowledge users (CIHR, 2004). In time, other Canadian research funders followed, including, but not exclusively, the Social Sciences and Humanities Research Council of Canada (SSHRCC), as well as provincial funders such as Alberta Innovates Health Solutions (AIHS), Nova Scotia Health Research Foundation (NSHRF), and Michael Smith Foundation for Health Research (MSFHR).

CIHR was among the first research funders to request a knowledge translation plan as part of the scientific proposal submission. They requested that researchers provide an account of how their research would contribute to the creation and application of health-related knowledge through a wide range of research and knowledge translation activities, including relevant collaborations and knowledge user partnerships. Researchers are permitted to budget for knowledge translation activities within the proposal submission, and this is a key facilitator for researcher buy in. Anecdotally, the request for a knowledge translation plan was met with some measure of alarm and confusion by the scientific community, likely because of a perceived lack of preparedness to address this demand. For the most part, researchers simply did not know what a knowledge translation plan was or how to develop one, and many simply did not perceive the relative advantage of engaging in knowledge translation. This is not surprising given that, as Bauer and colleagues (2015) noted, "historically, the research-to-practice gap has not been the concern of academic clinical researchers". Along this line, some expressed concern that sparse research dollars would be directed away from research toward knowledge translation activities that were perceived to be questionable in their intent, utility, and effectiveness. Mostly, however, scientists were lacking knowledge translation knowledge and skills, and were rather perplexed about the form and development of a knowledge translation plan. It was in this changing context that a unique opportunity for professional development emerged.

\section{Shifting the Research Paradigm: Changes at the Practice Level}

Alongside the changes taking place among research funders was a shift in knowledge translation practice in the clinical realm during this time. A range of institutions, including non-profit, research, academic, public health, and voluntary health organizations worked to re-vision their strategic plans to incorporate knowledge 


\section{Development of the Knowledge Translation Planning Template}

\section{Melanie Barwick}

translation, often instituting dedicated resources for knowledge translation practitioners to function as resident experts and knowledge brokers or intermediaries. Given that knowledge translation practice is an emerging profession within a dynamic landscape, it would be difficult to estimate how many individuals occupy knowledge translation roles across Canada. An informed guess would be a minimum of 173 individuals, based solely on the number of Canadian Knowledge Translation Community of Practice members (out of the full membership of 1422 individuals) who list knowledge translation within their job title (see www. ktecop.ca). A recent survey of knowledge translation practitioners across Canada (Barwick, Bovaird, \& McMillen, submitted for publication) found that knowledge translation planning and development was a role responsibility for $68 \%$ of the respondents $(\mathrm{N}=130)$. Despite the importance placed on this task, $26 \%$ report having no educational training that is relevant to their knowledge translation role, and $89 \%$ have learned knowledge translation on the job. Seventy-five percent would like to receive knowledge translation training, including how to develop a knowledge translation plan (51\%).

Research exploring the knowledge translation activities among health researchers suggests room for improvement. A study conducted with health researchers from three Alberta universities reported that applied researchers reported engaging in significantly more Mode II activities than basic researchers (i.e., activities that share research with decision makers and policy makers, to promote research knowledge creation and transfer based on the needs of knowledge users in the health care system) (Newton et al., 2007). Applied researchers also placed more importance on Mode II activities than their basic researcher counterparts. A similar study undertaken with UK-based publically funded applied and public health researchers reported that most recognized the importance of and appear committed to research dissemination, however most dissemination activity beyond the publishing of academic papers appears to be undertaken in an ad hoc fashion (Wilson et al., 2010). The conclusion appears to be that, while there is a good level of interest in knowledge translation, researchers need guidance and how best to plan, resource, and facilitate their knowledge translation activities.

\section{Shifting the Research Paradigm: Changes in Academia}

The knowledge translation landscape within academia is also undergoing a shift. Universities in Canada (see engagedscholarship.ca) and beyond (see ccph.memberclicks.net) are revising academic promotion criteria to include knowledge translation activities alongside the standard scholarship in teaching and research. By example, in the University of Toronto's Department of Psychiatry and Faculty of Medicine more broadly, faculty can go forward for promotion on the basis of their research, teaching, and a newer category of scholarship called creative professional activity, which includes knowledge translation activities. Creative professional activity is increasingly recognized, alongside research, educational scholarship and sustained clinical and teaching excellence, as a category of scholarship that captures valued contributions to the academic enterprise that are deserving of consideration for promotion. The University of Toronto's Faculty of Medicine recognizes creative professional activity under the following three broad categories: i) professional innovation and creative excellence (e.g., developing of an invention, development of new techniques, conceptual innovations, or educational programs); ii) contributions to the development of professional practices (e.g., in the form of leadership in the profession, or in professional societies, associations, or organizations that has influenced standards or enhanced the effectiveness of the discipline); and iii) exemplary professional practice (e.g., that which is fit to be emulated; is illustrative to students and peers; establishes the professional as an exemplar or role model for the profession; or shows the individual to be a professional whose behaviour, style, ethics, standards, and method of practice are such that students and peers should be exposed to them and encouraged to emulate them). Creative professional activities must be linked to research to provide an overall assessment of scholarly activity. (For additional information on the university's evaluation criteria, see University of Toronto, 2015).

\section{The Development of the Knowledge Translation Planning Template}

Although the emerging knowledge translation demands of the funding agencies have been key drivers for change in practice and academia, these shifts have been met by a lack of preparedness on the part of clinicians and researchers. However, importantly, the growing attention to knowledge translation across sectors has created an imperative for both researchers and practitioners to develop skills for knowledge translation planning as it relates to research, academia, or organizational activities. To this end, the Scientist Knowledge Translation Training course (Barwick et al., 2005) was developed through SickKids Research Institute and CHSRF funding (2004-2007) to assist researchers in de- 


\section{Development of the Knowledge Translation Planning Template}

\section{Melanie Barwick}

veloping their knowledge of knowledge translation, its application and relevance to their own research, and in the development of knowledge translation planning skills that could be applied to: i) research funding proposals and ii) to the subsequent conduct of successful projects to increase the impact of their work. During this time, the Knowledge Translation Planning Template was developed to assist with the knowledge translation planning task (Barwick, 2008, 2013).

The purpose of the Knowledge Translation Planning Template is to provide an evidence-informed framework for the development of a knowledge translation plan that incorporates what we recognize as the main components of knowledge translation. The Knowledge Translation Planning Template was informed by grey literature in knowledge translation planning (Goering et al., 2010; Reardon et al., 2006), the author's vision and experience, and two syntheses of evidence-based knowledge translation strategies for supporting practice change (Boaz et al., 2011; Grol \& Grimshaw, 2003). Two groups in Toronto - the Institute for Work and Health (www.iwh.on.ca) and the Health Systems Research Consulting Unit at the Centre for Addiction and Mental Health (camh.ca) - were pioneers in capturing the basic components of knowledge translation planning. The Institute for Work and Health developed a workbook (Reardon et al., 2006) that proposes a framework to support knowledge translation planning. The Health Systems Research Consulting Unit at the Centre for Addiction and Mental Health, under the leadership of Dr. Paula Goering, also developed a knowledge translation framework, which they disseminated through coursework and within a knowledge translation document prepared to support grant reviewers at CIHR (Goering et al., 2010).

The Knowledge Translation Planning Template was designed to guide researchers, clinical educators, and knowledge translation practitioners through the knowledge translation planning process in a stepwise manner such that the core elements of knowledge translation planning are considered. Importantly, the Knowledge Translation Planning Template is an evidence-informed tool. For instance, the tool requests identification of key knowledge translation strategies a core component of the template - and refers to the current state of the evidence base for knowledge translation strategies (Boaz et al., 2011; Grol \& Grimshaw, 2003). In addition, the tool captures plans and methods for integrated knowledge translation based on an extensive amount of academic literature that describes how the involvement of knowledge users in the research process will increase the uptake of research results and improve the relevance of research findings (Cargo \& Mercer, 2008; CIHR, 2013; Israel et al., 1998; Lomas, 2000; Macaulay et al., 2011). In contrast to open call researchers working in all types of health research, a CIHR evaluation of their knowledge translation funding found that researchers involved in integrated knowledge translation were more likely to report influencing their study stakeholders, health system/care practitioners, patients and consumers of healthcare, healthcare managers, healthcare professional organizations, federal/provincial representatives, community/municipal organizations, as well as consumer groups and charitable organizations (CIHR, 2013). Thus, the Knowledge Translation Planning Template is designed to support effective and evidence-informed knowledge translation of research to practice by knowledge translation practitioners and researchers alike. It is applicable across the health research pillars (i.e., basic, clinical, health services, and population health) and across sectors (i.e., health, mental health, education, social sciences, and environmental sciences).

Finally, reflecting on the Knowledge Translation Planning Template through the lens of the consolidated framework for implementation research (Damschroder et al., 2009), the tool meets several of the characteristics associated with implementation success: i) low cost and complexity; ii) careful attention to its design and quality; iii) strong evidence base; iv) trialability or the possibility to try its use and change course of action, if needed; and v) relative advantage, which is a user's perception of the advantage of implementing the tool versus an alternative solution.

\section{Structure and Educational Objectives}

The Knowledge Translation Planning Template is available as a downloadable static or fillable worksheet, and it is organized as 13 core planning steps/components:

1. Identifying the project partners

2. Degree of partner engagement

3. Partner roles in the knowledge translation planning

4. Knowledge translation expertise on team

5. Targeted knowledge users 


\section{Development of the Knowledge Translation Planning Template}

\section{Melanie Barwick}

\section{Research findings presented as main messages}

7. Knowledge translation goals, such as building awareness or interest, informing research or policy, or changing practice

8. Knowledge translation strategies to be used to meet the knowledge translation goals

9. Knowledge translation process, such as integrated or end of grant activities

10. Indicators of knowledge translation impact and evaluation metrics

\section{Resources needed to actualize the plan}

\section{Related budget items to include in funding proposals}

13. Details of how the knowledge translation strategies will be implemented

By using the Knowledge Translation Planning Template, the researcher or user learns the key components of knowledge translation and becomes better equipped to apply them in practice. Although these key components are elaborated upon in the related aforementioned workshop, the user can work through the tool independently given some background knowledge in knowledge translation. As such, the planning activity focuses on the application of new learning (i.e., Blooms revised taxonomy of learning domains; Pohl, 2000). By learning to actively plan, the user is able to demonstrate that they can use knowledge translation concepts in a new situation as they follow the steps to produce a knowledge translation plan that is relevant to their project or research endeavour. Use of the Knowledge Translation Planning Template also activates the user's ability to analyze the core components of knowledge translation, another higher-order learning objective, as the user outlines in stepwise fashion the core elements of the plan as it pertains to the project or research endeavour and describes the knowledge translation goals, strategies, and evaluation metrics for each targeted knowledge user. The user evaluates or makes judgments about the core components by selecting knowledge translation goals, strategies, processes (integrated or end of grant knowledge translation), and metrics. The final higherorder learning objective reflected in this exercise is the ability to create a plan, putting the component parts of the planning process together to form a type of logic model that will guide the knowledge translation activities for a project or research endeavour.

\section{Deployment and Accessibility}

The Knowledge Translation Planning Template is included as an educational component of two professional development opportunities: the Scientist Knowledge Translation Training Workshop (Barwick et al., 2005) and the Knowledge Translation Professional Certificate (Barwick et al., 2011). The Knowledge Translation Planning Template is available at no cost on the Internet at two locations:

- http://www.melaniebarwick.com/training.php

- http://www.sickkids.ca/Learning/AbouttheInstitute/

Programs/Knowledge-Translation/Resources/

LI-KT-Planning-Template-Form.html

In its most recent revision (2013), the tool outlines the entire planning process in successive columns and provides space for the user to write out the plan as it develops. No other materials are required. It is recommended that the plan be developed collaboratively by the research or project team, inclusive of knowledge users, as appropriate.

\section{Limitations}

Users with little knowledge in knowledge translation may experience some difficulties in using the tool without support. To address this, an e-learning module describing the core knowledge translation planning components and use of the tool is under development by the Knowledge Translation Program in the Learning Institute at the Hospital for Sick Children in Toronto (planned release, October 2016). A further limitation is that users with no Internet access or access to the knowledge translation courses mentioned above may not be aware of the tool or able to access it.

\section{Complementary Tools}

The Knowledge Translation Game (Barwick, 2009) is a card game that incorporates the core elements of knowledge translation planning, as defined by the Knowledge Translation Planning Template, and it is useful for active learning of the knowledge translation planning process. Knowledge Translation Game cards identify the process, knowledge translation strategies, and knowledge translation user audiences that are integral to a knowledge translation plan for a scenario depicted on knowledge translation scenario cards or for a project or research endeavour of the users' own choosing. The Knowledge Translation Game is available for purchase from Cvent (www.cvent.com/d/44qs3m). 


\section{Development of the Knowledge Translation Planning Template}

\section{Melanie Barwick}

\section{Impact Metrics and Evaluation}

Reach is a measure of impact insofar as it identifies connection with one's potential audience. Reach metrics indicate how far content is disseminated and to how big an audience. The Knowledge Translation Planning Template has been disseminated and taught to over 2,300 Scientist Knowledge Translation Workshop participants since its development in 2008, and to 242 Knowledge Translation Practitioner Certificate participants since 2010 . It has been viewed by over 20,000 unique visitors who have visited the website (www.melanie barwick.com) from 152 countries. From the perspective of engagement, it has been downloaded over 10,000 times between January 2014 and August 2016.

Since its development, several organizations and authors have developed similar tools and resources to assist in knowledge translation planning and activities, and many more have adopted the Knowledge Translation Planning Template in its original format (e.g., Canadian Centre for Substance Abuse; Parachute; Michael Smith Foundation for Health Research; EENet; York University Knowledge Mobilization Unit; Health Care Programs and Policy Directorate at Health Canada; Ontario Agency for Health Protection and Promotion). Others have, with permission provided earlier on in its developmental history, adapted the Knowledge Translation Planning Template for their own purpose (e.g., Institut national de santé public Québec; Health Care Programs and Policy Directorate at Health Canada). Adaptations are no longer encouraged or permitted to protect against violation of intellectual property. The tool is currently undergoing a translation to French. An extension version is under development by the Center on Knowledge Translation for Technology Transfer at the University of Buffalo to capture knowledge translation activities in the commercialization realm: (see tinyurl.com/hn7ge9l).

\section{Conclusion}

Several changes to the research, practice, and academic landscapes have encouraged and facilitated knowledge translation capacity building across Canada, and others are looking to Canada as they develop their own national capacity and scientist competencies (e.g., Australia, England, Ireland, Scotland). With the maximization of healthcare value becoming a global imperative, there is both an urgency to ensure health research is relevant and accessible to a range of knowledge users, and that science can have demonstrable impact including but reaching beyond contribution to research to inform behaviour, practice, service, and policy. As an evidence-informed knowledge translation planning tool, the Knowledge Translation Planning Template contributes to capacity building by improving knowledge translation knowledge and supporting knowledge translation planning amongst researchers and others responsible for bridging the research to practice gap. It is a widely disseminated innovation, crossing the borders of $78 \%$ of the world's countries, has been emulated widely, has been incorporated as a core knowledge translation planning tool in many organizations, and continues to be highly accessed eight years following its development.

\section{Acknowledgements}

The author thanks Dr. Raluca Barac for her comments on earlier drafts of this article.

\section{About the Author}

Melanie Barwick (PhD, CPsych) is a Senior Scientist in the Child Evaluative Sciences Program of the Research Institute, and Head of the Child and Youth Mental Health Research Unit (CYMHRU) in the Department of Psychiatry at SickKids in Toronto, Canada. She is also affiliated with the SickKids' Learning Institute where she conducts professional development in knowledge translation, and with the Centre for Global Child Health as a scientist and member of the leadership. She is an Associate Professor in the Department of Psychiatry and in the Dalla Lana School of Public Health at the University of Toronto. She chairs the Creative Professional Activity Committee for the Department of Psychiatry, and is a member of the Departmental Promotions Committee. She is an Executive Board member for AMREF Health Africa, the Children and Youth in Challenging Contexts (CCYC) Network Centre of Excellence and for the Global Implementation Initiative (GII), and she is an Associate Editor for the journal Evidence \& Policy. 


\section{Development of the Knowledge Translation Planning Template}

\section{Melanie Barwick}

\section{References}

Balas, E. A., \& Boren, S. A. 2000. Managing Clinical Knowledge for Health Care Improvement. In J. Bemmel \& A. T. McCray (Eds.), Yearbook of Medical Informatics 2000: Patient-Centered Systems: 65-70. Stuttgart, Germany: Schattauer Verlagsgesellschaft mbH.

Barwick, M. 2008. Knowledge Translation Planning Template. Toronto: The Hospital for Sick Children.

Barwick, M. 2009. The Knowledge Translation Game. Toronto: The Hospital for Sick Children.

Barwick, M. 2013. Knowledge Translation Planning Template (Revised). Toronto: The Hospital for Sick Children.

Barwick, M., Bovaird, S., \& McMillen, K. (in preparation). Building Capacity for Knowledge Translation Practitioners in Canada.

Barwick, M., Bovaird, S., Parker, K., McMillen, K., \& Warmington, K. 2011. Knowledge Translation Professional Certificate. Toronto: The Hospital for Sick Children.

Barwick, M., Butterill, D., Lockett, D. M., Buckley, L., \& Goering, P. 2005. Scientist Knowledge Translation Training. Toronto: The Hospital for Sick Children / Centre for Addiction in Mental Health.

Bauer, M. S., Damschroder, L., Hagedorn, H., Smith, J., \& Kilbourne, A. M. 2015. An Introduction to Implementation Science for the NonSpecialist. BMC Psychology, 3: 32.

http://dx.doi.org/10.1186/s40359-015-0089-9

Boaz, A., Baeza, J., Fraser, A., \& The European Implementation Score Collaborative Group (EIS) 2011. Effective Implementation of Research into Practice: An Overview of Systematic Reviews of the Health Literature. BMC Research Notes, 4: 212. http://dx.doi.org/10.1186/1756-0500-4-212

Cargo, M., \& Mercer, S. L. 2008. The Value and Challenges of Participatory Research: Strengthening Its Practice. Annual Review of Public Health, 29: 325-50.

http://dx.doi.org/10.1146/annurev.publhealth.29.091307.083824

CIHR. 2004. Innovation in Action: Knowledge Translation Strategy 20042009. Ottawa: Canadian Institutes of Health Research (CIHR). http://cihr-irsc.gc.ca/e/26574.html

CIHR. 2012. Final Report (Sample). Ottawa: Canadian Institutes of Health Research (CIHR).

http://cihr-irsc.gc.ca/e/documents/electronic_final_report_e.pdf

CIHR. 2013. Evaluation of CIHR's Knowledge Translation Program. Ottawa: Canadian Institutes of Health Research (CIHR). http://cihr-irsc.gc.ca/e/documents/knowledge translation_evaluation_report-en.pdf

Damschroder, L. J., Aron, D. C., Keith, R. E., Kirsh, S. R., Alexander, J. A., \& Lowery, J. C. 2009. Fostering Implementation of Health Services Research Findings into Practice: A Consolidated Framework for Advancing Implementation Science. Implementation Science, 4: 50. http://dx.doi.org/10.1186/1748-5908-4-50

Ellis, K. S. 2014. Knowledge Translation and the Governance of Health Research in Canada: A Critical Discourse Analysis. Doctoral Thesis. The University of Western Ontario.

http://ir.lib.uwo.ca/cgi/viewcontent.cgi?article=3663\&context=etd
Goering, P., Ross, S., Jacobson, N., \& Butterill, D. 2010. Developing a Guide to Support the Knowledge Translation Component of the Grant Application Process. Evidence \& Policy: A Journal of Research, Debate and Practice, 6(1): 91-102.

http://dx.doi.org/10.1332/174426410X483024

Grol, R. \& Grimshaw, J. 2003. From Best Evidence to Best Practice: Effective Implementation of Change in Patients' Care. The Lancet, 362(9391): 1225-1230. http://dx.doi.org/10.1016/S0140-6736(03)14546-1

Israel, B. A., Schulz, A., Parker, E., \& Becker, A. B. 1998. Review of Community-Based Research: Assessing Partnership Approaches to Improve Public Health. Annual Review Public Health, 19: 173-202. http://dx.doi.org/10.1146/annurev.publhealth.19.1.173

Lomas, J. 2000. Using 'Linkage and Exchange' to Move Research into Policy at a Canadian Foundation. Health Affairs, 19(3): 236-240. http://dx.doi.org/10.1377/hlthaff.19.3.236

Morris, S. Z., Wooding, S., \& Grant, J. 2011. The Answer Is 17 Years, What Is the Question: Understanding Time Lags in Translational Research. Journal of the Royal Society of Medicine, 104(12): 510-520. http://dx.doi.org/10.1258/jrsm.2011.110180

Nedjat, S., Gholami, J., Yazdizadeh, B., Nedjat, S., Maleki, K., \& Majdzadeh, R. 2014. Research's Practice and Barriers to Knowledge Translation in Iran. Iranian Journal of Public Health, 43(7): 968-980.

Newton, M. S., Estabrooks, C. A., Norton, P., Birdsell, J. M., Adewale, A. J., \& Thornley, R. 2007. Health Researchers in Alberta: An Exploratory Comparison of Defining Characteristics and Knowledge Translation Activities. Implementation Science, 2:1.

http://dx.doi.org/10.1186/1748-5908-2-1

Pohl, M. 2000. Learning to Think, Thinking to Learn: Models and Strategies to Develop a Classroom Culture of Thinking. Cheltenham, Australia: Hawker Brownlow.

Reardon, R., Lavis, J., \& Gibson, J. 2006. From Research to Practice: A Knowledge Transfer Planning Guide. Toronto: Institute for Work and Health.

https://www.iwh.on.ca/system/files/at-work/knowledge translatione_planning_guide_2006b.pdf

Tetroe, J. M., Graham, I. D., Foy, R., Robinson, N., Eccles, M. P., Wensing, M., Durieux, P., Legare, F., Palmhøj Nielson, C., Adily, A., Ward, J. E., Porter, C., Shea, B., \& Grimshaw, J. M. 2008. Health Research Funding Agencies' Support and Promotion of Knowledge Translation: An International Study. The Milbank Quarterly, 86(1): 125-155.

http://dx.doi.org/10.1111/j.1468-0009.2007.00515.x

University of Toronto. 2015. Manual for Academic Promotion to Associate and Full Professor. Toronto, ON: Faculty of Medicine, University of Toronto.

http://www.psychiatry.utoronto.ca/wpcontent/uploads/2011/02/ManualforAcademicPromotion2015.pdf

Wilson, P. M., Petticrew, M., Calnan, M. W., \& Nazareth, I. 2010. Does Dissemination Extend beyond Publication? A Survey of a Cross Section of Public Funded Research in the UK. Implementation Science, 5: 61.

http://dx.doi.org/10.1186/1748-5908-5-61 